\title{
Technology
}

\section{Ultrasound computerized tomography in (bio)medical engineering and clinical medicine - a new approach}

\section{Emre Erten and Andreas Otte*}

Division of Biomedical Engineering, Department of Electrical Engineering and Information Technology, Offenburg University, D-77652 Offenburg, Germany

Ultrasound computerized tomography (USCT) is a nondestructive, non-ionizing tomographic procedure interesting for material control in (bio)medical engineering, but also for a variety of clinical diagnoses where high-resolution 3D-tomographic scanning is important, such as the detection of early breast cancer.

To verify this hypothesis, various objects and standardized phantoms were tested in a proof-of-concept pilot study using a Gampt (Gesellschaft für Angewandte Medizinische Physik und Technik mbH, Merseburg, Germany) USCT device, equipped with two $2 \mathrm{MHz}$ probes. One probe was switched for permanent transducing and the other probe for continuous receipt of the signal, while the object was translated and rotated in a special sample holder. For the scans, different parameters
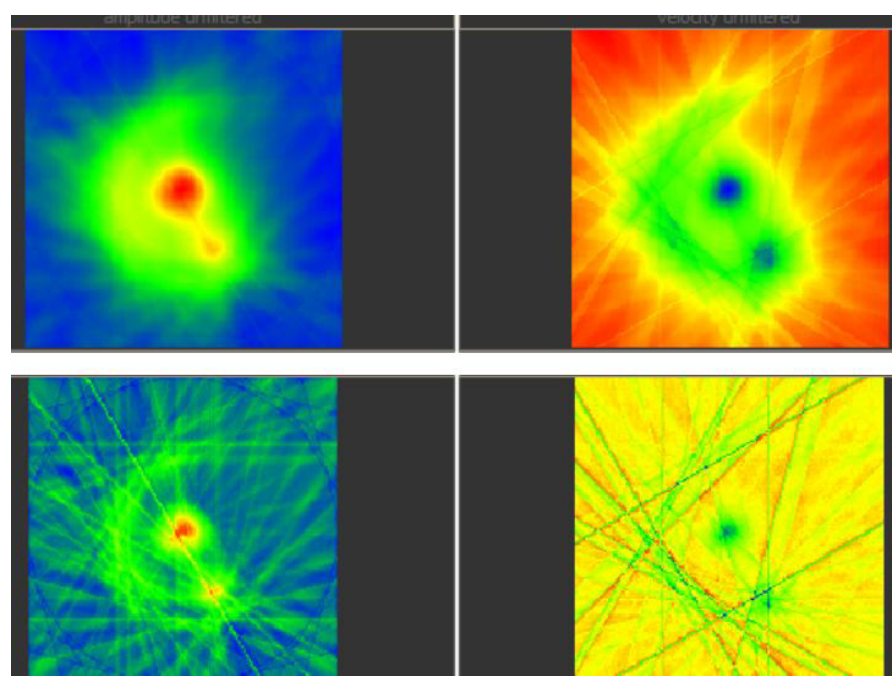

Figure 1. USCT scan of a ginger tuber, transaxial slice. Left column: amplitude images, right column: velocity images; upper row: unfiltered, lower row: with Shepp-Logan filter.

Copyright: (C)2016 Erten E. This is an open-access article distributed under the terms of the Creative Commons Attribution License, which permits unrestricted use, distribution, and reproduction in any medium, provided the original author and source are credited. of the device were chosen and modified. Tomographic ultrasound attenuation and time-of-flight (velocity) images were reconstructed (Radon transformation, Shepp-Logan filter) [1].

First data of this "new, old" method are promising (a non-clinical example can bee seen in Figure 1) and yield potential new aspects on the diagnostic value of ultrasound by the use of computerized tomograms in contrast to normal data acquisition by the use of the ultrasound's reflectivity, as it is established in clinical routine sonography for years.

\section{References}

1. Radon J (1917) Über die Bestimmung von Funktionen durch ihre Integralwerte längs gewisser Mannigfaltigkeiten. In: Berichte über die Verhandlungen der KöniglichSächsischen Gesellschaft der Wissenschaften zu Leipzig. Mathematisch-Physische Klasse Band 69: 262-277.

Correspondence to: Prof. Andreas Otte, MD, Division of Biomedical Engineering, Department of Electrical Engineering and Information Technology, Offenburg University, D-77652 Offenburg, Germany, Tel. +49 781 205-338; Fax: +49 781 205-45338; Email: andreas.otte@hs-offenburg.de

Key words: ultrasound computerized tomography, biomedical engineering, cancer diagnostics

Received: October 10, 2016; Accepted: November 21, 2016; Published: November 23, 2016 